\title{
Left ventricular assist device therapy instead of conventional cardiac surgery in high-risk patients: To boldly go where no one has gone before?
}

\author{
Nader Moazami, MD
}

From the Department of Cardiothoracic Surgery, NYU Langone Health, New York, NY.

Disclosures: Author has nothing to disclose with regard to commercial support.

Received for publication June 5, 2018; revisions received June 5, 2018; accepted for publication June 5, 2018; available ahead of print July 14, 2018.

Address for reprints: Nader Moazami, MD, Department of Cardiothoracic Surgery, NYU Langone Health, 530 1st Ave, Suite 9V, New York, NY 10016 (E-mail: nader.moazami@nyumc.org).

J Thorac Cardiovasc Surg 2018;156:1541-2

$0022-5223 / \$ 36.00$

Copyright (C) 2018 by The American Association for Thoracic Surgery

https://doi.org/10.1016/j.jtcvs.2018.06.019

With improved outcomes with mechanical circulatory support (MCS), left ventricular assist devices (LVADs) have now become a well-established treatment option for patients with end-stage heart failure who have failed medical therapy. The success with LVADs has been mainly in the domains of improved survival and quality of life compared with continued medical therapy. In the search for pathways that will continually improve survival outcomes for our patients, it is a natural extension of common sense to logically consider LVAD therapy for patients who are at a higher risk of mortality with conventional surgery.

In this issue of the Journal, Thalji and colleagues, ${ }^{1}$ from the Mayo Clinic, have attempted to define risk factors associated with mortality after conventional cardiac surgery in high-risk patients with an ejection fraction (EF) less than $25 \%$. The procedures consist mainly of coronary artery bypass grafting \pm valve surgery, and the study spans from 1993 to 2014. The main theme of this well-written article is that in patients aged more than 70 years, New York Heart Association (NYHA) IV symptoms and a history of surgery confer a higher, additive risk of perioperative mortality. In the concluding remarks, they allude to the potential that for these subsets of patients, perhaps LVAD therapy should be considered.

The risk factors identified by Thalji and colleagues ${ }^{1}$ are well engrained in the minds of most cardiac surgeons embarking on high-risk surgery. After all, left ventricular impairment, NYHA class IV, emergency surgery, older age, prior cardiac surgery, use of intra-aortic balloon pump, and peripheral vascular disease are well known to the majority of us to incrementally, and perhaps additively, increase the risk of surgery. Perhaps not mentioned, but also high on the list, are renal and pulmonary insufficiency. Does that necessarily mean that we should now be more aggressive with LVAD therapy instead? This is where I am troubled by this thought process.

Although EF less than $25 \%$ is a necessary condition for LVAD consideration and a surrogate for poor outcomes, we

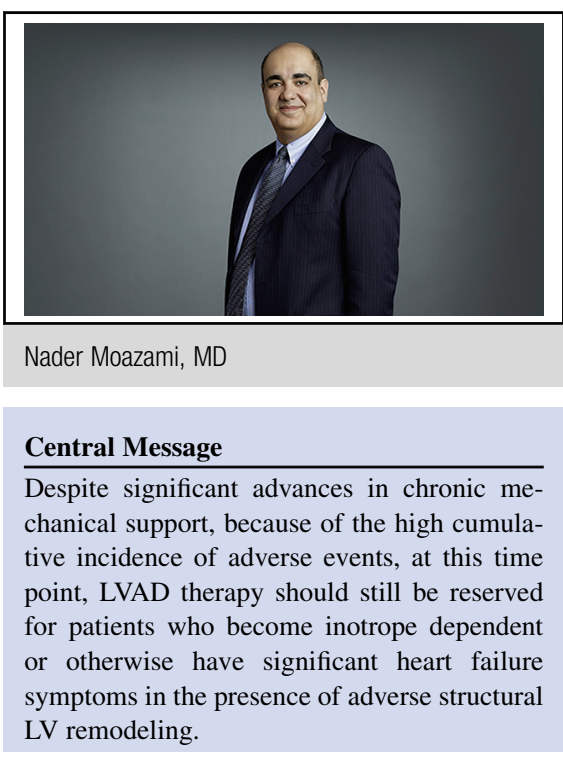

See Article page 1530 .

know that it is a poor marker for exercise capacity and quality of life. In fact, many patients with EF less than $25 \%$ can be well managed with current medical therapies. The hallmark for needing LVAD therapy continues to be the presence of significant heart failure symptoms manifested by limited exercise tolerance and fluid overload, but more important, the need for inotropic support. In the Interagency Registry for Mechanically Assisted Circulatory Support, more than $85 \%$ of patients are taking at least 1 inotrope at the time of LVAD implantation (levels 1-3 combined), a feature that clearly portends poor short-term survival in the absence of MCS therapies. To consider patients who are not dependent on inotropes and referred for cardiac surgery for LVAD therapy is indeed bold, and previous attempts to use LVADS in "less sick" patients have been unfavorable or abandoned in view of the higher rate of adverse events, which is unfortunately still all too common with LVAD therapy. In addition, in this retrospective study, as is the case with all retrospective studies, patient-specific characteristics such as hemodynamics, presence or absence of pulmonary hypertension, other concomitant structural abnormalities, the degree of preoperative optimization, and many more variables are lost. Simplification of risk assessment is not an option when the stakes are too high 
in a particularly difficult patient population involving complex decisions.

For the longest time, in the majority of studies, survival has been the yardstick by which success is measured. Unfortunately, in the absence of a prospective trial, this metric falls short of defining success because the morbidity associated with therapies is hidden. More important, the impact of surgery on relieving the patient's index symptoms is poorly defined. If patients with dilated cardiomyopathy and functional mitral regurgitation undergo valve repair, survive the perioperative period, but are discharged to a long-term care facility and continue to be symptomatic, have we really succeeded? It is important that in considering therapies for patients in heart failure, symptomatic relief, improvement in quality of life, or some measure of functional status should be evaluated.

Finally, although results of survival with LVAD therapy have significantly improved in the era of continuous rotary flow devices, the composite of complications associated with these devices remains unacceptably high for it to be considered liberally for the majority of patients. In particular, stroke remains a limiting factor, and early or prophylactic LVAD implantation is to be discouraged at this time. In the ROADMAP trial, ${ }^{2} 200$ non-inotropedependent patients with predominant heart failure symptoms were randomized to continued medical therapy versus LVAD. Although survival and quality of life were improved with LVAD therapy, the higher frequency of adverse events with LVADs makes the wider application of MCS questionable.

The study by Thalji and colleagues ${ }^{1}$ highlights that NYHA IV and reoperative surgery are important contributors to perioperative mortality, likely reflecting on the premise that these patients had advanced heart failure. This is an important fact, but perhaps a better indicator would be parameters that focus on adverse structural remodeling of the heart combined with hemodynamic markers that are congruent with the advanced presentation of heart failure as the predominant feature. Should a patient with an EF less than $25 \%$, NYHA class IV, and left ventricular enddiastolic dimension of $7 \mathrm{~cm}$ undergo high-risk coronary artery bypass grafting or be offered LVAD therapy? This may seem to be largely unanswered, but in the current era, my suggestion would be continued medical therapy and watchful waiting. We do not need to boldly go down the route of operating on the majority of these patients too early. Time is our friend.

\section{References}

1. Thalji NM, Maltais S, Daly RC, Greason KL, Schaff HV, Dunlay SM, et al. Risk of conventional cardiac surgery among patients with severe left ventricular dysfunction in the era of mechanical circulatory support. J Thorac Cardiovasc Surg. 2018; 156:1530-40.e2.

2. Estep JD, Starling RC, Horstmanshof DA, Milano CA, Selzman CH, Shah KB, et al. Risk assessment and comparative effectiveness of left ventricular assist device and medical management in ambulatory heart failure patients: results from the ROADMAP study. J Am Coll Cardiol. 2015;66:1747-61. 